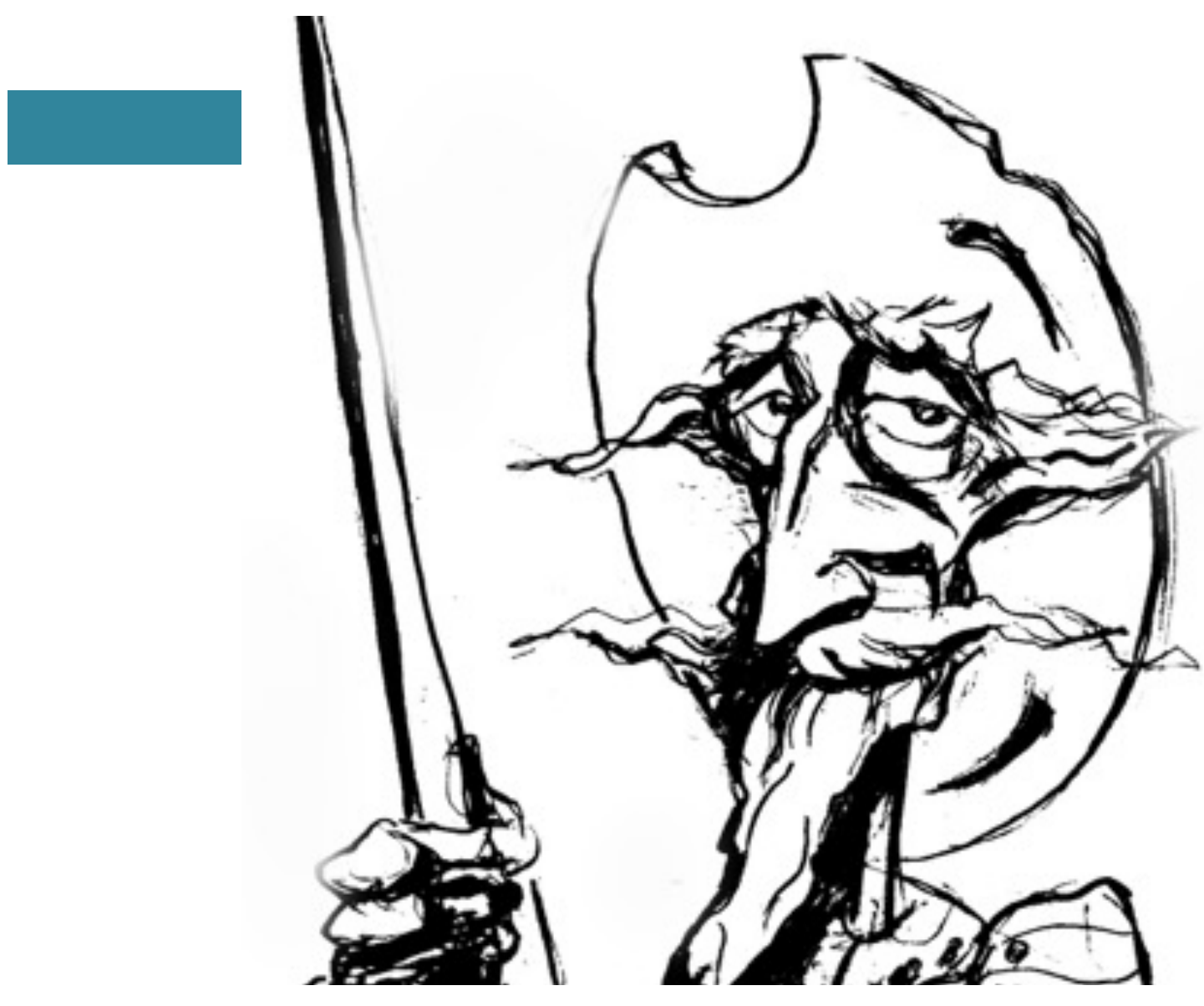

La historia conceptual y las distorsiones cognitivas del uso acrítico del concepto "Estado"

[Claudio Sergio Ingerflom] 


\title{
La historia conceptual y las distorsiones cognitivas del uso acrítico del concepto "Estado"
}

\author{
The Conceptual history and the cognitive distortions by the uncritical \\ utilization of "State" concept
}

ClAUdio SERGIO INGERFLOM

\section{Resumen}

Los conceptos políticos europeo-occidentales, que constituyen la razón de ser original de la Historia conceptual, no son neutros sino que nacen "deformados" por la historia particular de su lugar de origen. Partiendo de esta premisa, este artículo se propone destacar la valía de un abordaje en clave histórico-conceptual como teoría e investigación histórica al mismo tiempo en tierras extrañas al área lingüística germana, donde aquella se ha forjado. El caso ruso es el elegido para ilustrar tal propósito. Un análisis minucioso sobre el empleo del concepto "Estado" por parte de la historiografía rusa adherida al paradigma estatalista occidentaldesnuda las distorsiones que se produjeron debido a la utilización acrítica de tal concepto, contraponiéndola al material empírico aportado por esa misma historiografía.

\section{Palabras clave}

Historia conceptual - Estado - paradigma estatalista - Rusia

\begin{abstract}
The political European-western concepts, which found the originality of the conceptual History, are not neutral. They're born "deformed" by their particular history. Based on this, the following article proposes to bring out the importance of the conceptual-history studies as theory and historical research both at the same time, outside the linguistic German area. The Russian case illustrates this purpose. A thorough analysis of the utilization of the "State" concept in the Russian historiography -attached to the "State" western paradigm- reveals the distortions produced by an uncritical utilization of such concept, and opposes it to the empirical documentation provided by the historiography itself.
\end{abstract}

Key words

Conceptual history - State - State Paradigm Russia

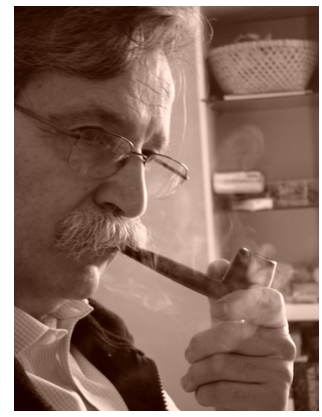

Recibido con pedido de publicación el 30 de septiembre de 2017

Aceptado para su publicación el 5 de noviembre de 2017

Versión definitiva recibida el 26 de diciembre de 2017

Claudio Sergio Ingerflom, Secretario de investigación, Escuela de Humanidades, Director del Centro de Estudios de Historia Conceptual, Universidad Nacional de San Martin, Argentina; e-mail: claudio.ingerflom@gmail.com

Esta obra se publica bajo licencia Creative Commons. Atribución-NoComercial-CompartirIgual 4.0 Internacional

(oc) EY-NC-SA

Ingerflom, Claudio Sergio "La historia conceptual y las distorsiones cognitivas del uso acrítico del concepto 'Estado'", Prohistoria, Año XX, núm. 28, Homenaje a Juan Carlos Garavaglia, dic. 2017, pp. 25-47.

Juanca: gracias. Hasta la vista hermano 


\section{El propósito del artículo ${ }^{1}$}

El concepto "Estado", usado para definir una realidad política o como categoría heurística para investigar el pasado (la famosa "construcción del Estado"), se encuentra en el centro de los estudios históricos. Funciona generalmente a través del paradigma analítico "estado-sociedad", que domina nuestra disciplina desde mediados del siglo XIX. La importancia otorgada al "Estado" o a la "sociedad" como "motores de la historia", por ejemplo rusa, ha variado. Pero esas variaciones son internas al paradigma. Paralelamente a esta tendencia dominante, no faltaron los llamados a la prudencia en el manejo del concepto "Estado" en el caso de la historia rusa. ${ }^{2}$ Por mi parte he cuestionado la pertinencia del concepto como categoría de análisis de esa misma historia y en consecuencia la pertinencia del paradigma. ${ }^{3} \mathrm{El}$ terreno elegido para este estudio

\footnotetext{
${ }^{1}$ El presente artículo es una versión considerablemente ampliada de mi intervención en una conferencia organizada en Barcelona por Juan Carlos Garavaglia y publicada en GARAVAGLIA, Juan Carlos - BRADDICK, Michael J. and LAMOUROUX, Christian (eds.) Serve the Power(s), Serve the State. America and Eurasia, Cambridge Scholars Publishing, Cambridge, 2016, pp. 222243. Para mayor confort del lector que no domina el idioma ruso, no utilizo ninguno de los sistemas internacionales de transliteración ni los signos diacríticos adoptados para los textos académicos. He transcripto las letras rusas más simplemente, según la fonética española, incluyendo los nombres propios. Las excepciones son escasas y tienen que ver con los sonidos no existentes en nuestra lengua, para los cuales empleo la transcripción inglesa (zh, sh, shch) o con nombres propios que ya han adquirido notoriedad.

${ }^{2}$ Se ha estimado que la construcción del Estado permanecía incompleta aún en los siglos XIX y XX y se ha considerado también que la organización política soviética no se inscribía en un orden estatal. Ver Thomas Lowit, "Y a-t-il des Etats en Europe de l'Est?", Revue française de sociologie, XX, 1979, pp. 431-466 ; AMSTRONG, John A. Nations before Nationalism, University of North Carolina Press, 1982, pp. 129-130; los comentarios de CATALANO, Pierangelo Popoli e spazio romano tra diritto e profezia Atti del III Seminario Internazionale di Storici "Da Roma alla Terza Roma. Documenti e Studi. Studi III (1983)", Edizioni scientifiche italiane, Napoli, 1986, XVIII-XX; LeDONNE, John P. Ruling Russia. Politics and Administration in the Age of Absolutism 1762-1796, Princeton, 1984, VII, pp. 13-17, p. 349; Absolutism and the Ruling Class: the Formation of the Russian Political Order, 1700-1825, Oxford University Press, Oxford, 1991, pp. 19, 56-57, 60, 92, 112 y 311; RIEBER, Alfred J. "Landed Property, State Authority, and Civil War", vol. 47, Slavic Review, 1988, p. 31; ROSENBERG, William "Social Mediation and state construction(s) in revolutionary Russia", Social History, vol. 19, núm. 2, 1994; MARKWICK, Roger "What kind of state is the Russian State - if there is one?", Journal of communist studies and transition politics, dec. 1999, vol. 15, núm. 4 pp. 111-130; DIXON, Simon The Modernisation of Russia, 1676-1825, Cambridge University Press, New York, 1999, p. 256; HOSKING, Geoffrey Russia and he Russians. A History from Rus to the Russian Federation, The Penguin Press, London, 2001, pp. $190 \mathrm{y}$ 240; KHARKHORDIN, Oleg "What is the State? The Russian Concept of Gosudarstvo in European Context", History and Theory, 2001, vol. 40, núm. 2, pp.206-240; Main Concepts of Russian Politics, University Press of America, Lanham, 2005, pp. 1-40; GETTY, Arch Practicing Stalinism. Bolshevism, Boyars, and the persistence of tradition, Yale University Press, New Haven and London, 2013; RITTERSPORN, Gábor Anguish, Anger and Folkways in Soviet Russia, University of Pittsburgh Press, Pittsburgh, 2014, p. 7. Sin embargo, en mi conocimiento, la pertinencia del paradigma para la historia rusa no ha sido objeto de un debate específico. Hemos tenido a pesar de todo un intercambio estimulante en la mesa redonda "Should historians call Russia a State?" en la American Association for the Advancement of Slavic Studies (AAASS) de New Orleans en 2007, presidida por Valerie Kivelson, con la participación de Nancy Kollmann, John LeDonne, Daniel Rowland y el autor de este artículo.

3 INGERFLOM, Claudio El revolucionario profesional. La construcción política del pueblo, Prohistoria, Rosario, 2017 (ver el capítulo 1: "Rusia: un Imperio sin Estado"); Le Tsar c'est moi. L'imposture permanente d'Ivan le Terrible à Vladimir Poutine, Puf, Paris, 2015 (ver los capítulos $3 \mathrm{y}$ 5), ahora en español, Editorial Guillermo Escolar, Madrid, 2017; “Oublier l'Etat pour comprendre la Russie? (XVI ${ }^{\mathrm{e}}$ XIXe siècles)", Revue d'Etudes Slaves, 66, 1 (1994), pp. 125-134 (en español: Prohistoria, Rosario, 1997); "Sobre el concepto de Estado en la historia de Rusia", Historia Contemporánea, dossier "Pueblo, ciudadanía y otros conceptos políticos", Bilbao, España, 2004 (I), 28, pp. 53-60; “Novoevropeiskaia paradigma gosudarstvennosti (El moderno paradigma estatalista)", Rossiia XXI, núm. 2, 2011, Moscú, p. 110-127; “Lealtad al Estado o al
} 
crítico es el de la historia rusa. Pero en la medida en que los presupuestos teóricos del paradigma son generales y su uso no se limita a la historia rusa -al contrario, la historiografía rusa lo tomó prestado a la historiografía "occidental"-, esta investigación se inscribe en un amplio debate actual sobre el aparato conceptual de nuestra profesión. ${ }^{4}$

En ese debate, las proposiciones teóricas surgidas de la historia conceptual (Begriffsgeschichte) se han revelado las más efectivas por su radical potencial crítico y por el resultado de las investigaciones concretas elaboradas en su surco. Sin embargo, como es sabido, el conjunto de la obra de Koselleck concierne ante todo el espacio germano y los países cercanos, en primer lugar Francia. El famoso Lexicon, ${ }^{5}$ esos 8 gigantescos volúmenes de los cuales él fue el verdadero arquitecto, ${ }^{6}$

"seeks to determine how German speakers perceived,
conceptualized, and incorporated into their vocabulary those
accelerated changes that took place between the Enlightenment,
the French Revolution, and the Industrial Revolution."7

En ese sentido, una investigación en clave histórico-conceptual supone, que se trate de Rusia, del espacio rioplatense o de cualquier otro que no sea Europa occidental, poner a prueba las premisas teóricas de la Historia conceptual, es decir no ignorar la preocupación por la capacidad y la utilidad de la Historia conceptual a confrontar con historias ajenas a la que la vio nacer.

Los límites señalados por Koselleck en las líneas que acabo de citar son explícitos: los del mundo germano-hablante. La dificultad que no podemos esquivar es aquella a la que se refiere Dipesh Chakrabarty ${ }^{8}$ y que podríamos formular así: si los conceptos políticos europeo-occidentales que constituyen la razón de ser original de la Historia conceptual no son neutros sino que nacen "deformados" por la historia particular de su lugar de origen $-y$ al mismo tiempo poseen vocación universal- ¿cómo conducir una investigación históricoconceptual de áreas culturales que les son extrañas sin reproducir esa misma extrañeza entre la Begriffsgeschichte y las historias de otros mundos? Cuando los estudios histórico-conceptuales no tienen como objetivo el área alemana, se

\footnotetext{
Monarca. Los juramentos de fidelidad en el siglo XVIII a la luz de la historia conceptual. El caso ruso", Prohistoria, XIII, Rosario, 2009, pp, 147-165, retomado en "'Loyalty to the State' under Peter the Great? Return to the sources and the historicity of concepts", in BULLOCK, Philip BYFORD, Andy - INGERFLOM, Claudio et al. (eds.) Loyalties, Solidarities and Identities in Russian Society, History and Cuture, School of Slavonic and East European Studies, University College London, London, 2013, pp. 3-19.

${ }^{4}$ Para un panorama más vasto de la renovación de la historia política de la modernidad y del Estado, ver los artículos de SCHAUB, Jean-Frédéric "La Peninsola Iberica nei secoli XVI e XVII: la questione dello Stato", Studi storici, 36, 1, 1995, pp. 9-49; "Le Temps et l'Etat: vers un nouveau régime historiographique de l'Ancien régime français", Quaderni Fiorentini per la storia del pensiero giuridico moderno, Giuffrè, Milán, 25, 1996, pp. 127-181; “La notion d'Etat moderne estelle utile?", Cahiers du Monde Russe, 2005, 46/1-2.

${ }^{5}$ BRUNNER, Otto - CONZE, Werner - KOSELLECK, Reinhart Geschichtliche Grundgebriffe. Historisches Lexicon zur Politisch-soziaen Sprache in Deutschland, Klett-Cotta, Stuttgar, 1972.

${ }^{6}$ DUTT, Carsten "Epilogo", en KOSELLECK, Reinhart Historias de Conceptos. Estudios sobre semántica y pragmática del lenguaje político y social, Trotta, Madrid, 2012, p.294.

${ }^{7}$ KOSELLECK, Reinhart "A Response", in LEHMAM, Hartmut and RICHTER, Melvin (eds.) The Meaning of Historical Terms and Concepts. New Studies on Begriffsgeschichte, German Historical Institute, Washington DC, Occasional Paper núm. 15, 1996, p. 69.

${ }^{8}$ CHAKRABARTY, Dipesh Al Margen de Europa. Pensamiento poscolonial y diferencia histórica, Tusquets, Barcelona, 2008.
} 
han concentrado principalmente en los problemas de traducción ${ }^{9}$ de los conceptos europeo-occidentales y en el destino de estos en países europeos de recepción y en otros mundos. ${ }^{10}$ En esos trabajos se ha puesto en evidencia la traducción entre culturas $-\mathrm{y}$ no solo entre lenguas- así como la diversidad de las formas de conceptualizar -superando la noción de influencia unidireccional. ${ }^{11}$

La eficacia del uso de la Begriffsgeschichte para lo que se ha recientemente designado como la "no Europa"12 depende, por un lado, de si se toman o no las precauciones metodológicas necesarias. En este plano, Koselleck ha desbrozado parcialmente el camino, cuando, una vez expuestos los límites geográficos-lingüísticos de su Lexicon, redobla su advertencia, al quitarle valor de ejemplo a un término suyo -Sattelzeit-que sin embargo, sigue generalmente siendo, aunque discutido, percibido como una de sus categorías centrales. Esta noción define un periodo que, según una idea muy difundida, una investigación en clave histórico-conceptual debería identificar sí o sí en cualquier historia. Sin embargo Koselleck desligó esa categoría de su método:

"Initialy conceived as a catchword in a grant application for funding the Lexicon, this concept has come to obscure rather than to advance the project. Perhaps Schwellenzeit (treshold period) would have been a less ambiguous metaphor. In any case, hypotheses about the existence of such a period play no part in the method used in Begriffsgeschichte."13

En otras palabras, Koselleck vacuna al método contra el germanocentrismo y más ampliamente el europeocentrismo, diciéndole a los investigadores que Sattelzeit (o Schwellenzeit) no designa una estructura histórico-universal sino aquella que en tierras germanas constituyó el periodo de transición entre la modernidad temprana y la Alemania moderna, aproximadamente entre 1750 y 1850, y va más lejos aún planteando que se trata de una estructura histórica que puede hallarse en otras historias o no: "The Sattelzeit is neither an ontological notion nor is tied to a single national

\footnotetext{
${ }^{9}$ A título de ejemplo: RICHTER, Melvin "Mais do que uma via de mão dupla: analisando, traduzindo e comparando os conceitos politicos de outras culturas", en FERES JÚNIOR, João JASMIN, Marcelo História dos Conceitos. Diálogos transatlânticos, PUC, Rio de Janeiro, pp.21-29; PERNAU, Margrit "Transkulturelle Geschichte und das Problem der universalen Begriffe. Muslimische Bürger im Delhi des 19. Jahrhunderts", SCHABLER B. (Hrsg) Areas studies un die Welt. Weltregionen und neue Globalgeschichte, Wien, 2007, pp. 117-150; el Diccionario de conceptos políticos fundamentales finlandeses fue dirigido por HYVÄRINEN, M. - KURUNMÄKI, J. -PALONEN, K. - PULKINEN, T. - STENIUS, H. Käsitteet liikkeessä. Suomen polittisen kultuurin käsitehistoria, Tampere, 2003.

${ }^{10}$ La experiencia del Diccionario político y social del mundo Iberoamericano, CEPC, Madrid, t. 1 (2009) y t.2 (2014), bajo la dirección de Javier Fernández Sebastián es ejemplar ya que el espacio cultural luso-hispano-americano con dos lenguas tan afines y comunes a ambas orillas del Atlántico hace de la comparación y del devenir de los conceptos en un conjunto dispar de países los momentos esenciales de los estudios. Una mirada aunque sea rápida de la publicación periódica Contributions to the History of Concepts

(http://www.berghahnjournals.com/view/journals/contributions) demuestra que aún sobre el territorio europeo, las investigaciones han ido más allá de los solos conceptos, para abarcar problemas como la estructura temporal de historias nacionales y otros.

${ }^{11}$ Agradezco a Noemí Goldman sus valiosos comentarios sobre este punto.

${ }^{12}$ MILLER, Alexséi - SDVIZHKOV, Denis - SCHIERLE, Ingrid "Predislovie" (Prólogo), en Poniatiia o Rossii: $\mathrm{K}$ istoricheskoi semantike imperskogo perioda (Conceptos sobre Rusia: hacia una semántica histórica del periodo imperial), NLO, Moscú, 2012, p.33.

${ }^{13}$ KOSELLECK, Reinhart "A Response", cit., p. 69. La cursiva me pertenece, CI.
} 
language" ${ }^{14}$ Entiendo que si pensamos que en toda historia hay en un momento dado una sucesión más o menos lineal y progresiva del Antiguo régimen a veces llamado "pre-moderno" a la Modernidad, estamos obligados a identificar un periodo de transición. Al afirmar que el período de transición no es constitutivo del ser de la historia, Koselleck parece decir que no hay una sola forma de entrar en la modernidad, lo que abre la vía a pensar que no hay tampoco para él una única modernidad. Giuseppe Duso ha sido en este sentido explícito; su propuesta es la de

"una estrecha conexión entre historia conceptual y filosofía
política, e incluso su identidad, si el trabajo histórico conceptual
se entiende en su dimensión crítica y radical, y si la filosofía
política no se entiende como una construcción abstracta de
nuestra mente [...] como si no estuviésemos obligados a pensar en
el ámbito de una realidad en la que se dan las relaciones
políticas."15

Podríamos agudizar aún más la preocupación a la que vengo haciendo referencia, para confrontar ya no con el método sino con la historia conceptual como teoría e investigación histórica al mismo tiempo. Situémonos entonces en tierras extrañas, en historias que transcurren en una lengua que no pertenece ni a la familia latina ni a la subfamilia germana, que dejan ver sedimentos semánticos a la vez muy antiguos y aun funcionales, relacionando épocas lejanas de la Schwellenzeit alemana, o cuyas tradiciones de pensamiento se han forjado sin, o con una muy débil, herencia filosófica greco-latina y fuera de la tradición del derecho romano. Separados, estos factores son frecuentes en el mundo; la historia rusa tiene el dudoso privilegio de poseerlos todos. La extrañeza tiene la ventaja de poner a prueba la Historia conceptual exigiéndole toda su capacidad heurística, pues una alteridad de esa intensidad -que podemos relativizar si pensamos en historias como la china o la japonesa, exteriores ${ }^{16}$ a Europa, mientras que la historia rusa tiene el mismo teclado original con el cual se escribió buena parte de ella: la Biblia- requiere mucho más que simples precauciones metodológicas: otras condiciones parecen indispensables, de las cuales evocaré dos a continuación. Una concierne la conciencia teórica del investigador, la otra exige tomar en serio a los actores populares, reconociéndoles la capacidad de ser sujetos de su propia noesis.

Si la Historia conceptual se reduce a un método, aun manejado con precaución o a una (sub)disciplina ancilar de la historia social, ella devendría aporética y difícilmente escaparía al reproche de europeocentrismo. La Historia conceptual no cumplirá en tierras extrañas con los objetivos que ella se postuló con respecto al occidente europeo y no respetará sus propias premisas teóricohermenéuticas si no se desplaza enteramente en tanto que ciencia, en tanto que Historia -teoría e investigación de terreno-, sobre este último. Esto supone

"un modo de entender y practicar la historia conceptual, que tiene su dimensión específica y en la cual el elemento filosófico resulta determinante" ${ }^{\prime 17}$

\footnotetext{
${ }^{14}$ KOSELLECK, Reinhart "A Response", cit.

${ }^{15}$ DUSO, Giuseppe "Historia conceptual como filosofía política", en CHIGNOLA, Sandro DUSO, Giuseppe Historia de los conceptos y filosofía política, Biblioteca Nueva, Madrid, 2009, p. 160. La cursiva me pertenece, $\mathrm{CI}$.

${ }^{16}$ JULLIEN, François - MARCHAISE, Thierry Penser d'un dehors (la Chine), Seuil, Paris, 2000, pp. 247-263.

${ }^{17}$ DUSO, Giuseppe “Historia conceptual como filosofía política”, cit., p. 160.
} 
Se ha afirmado recientemente que la Historia conceptual

"es a la vez histórica y filosófica, y que no puede ser la una sino es la otra [...] De eso se trata, de teoría sin la cual no es posible la investigación histórica." 18

Inútil pues detenerse solo en los aspectos metodológicos de la historia conceptual -para eventualmente y ya adaptados, aplicarlos a otros mundos. El desafío consiste en, desde el comienzo, o sea desde la definición misma del tema, desde la selección y lectura de las fuentes y desde la elaboración de las primeras hipótesis, de construir la investigación con la mayor conciencia posible de las premisas teóricas de la Begriffsgeschichte en una diversidad que ya se ha expandido más allá del corpus koselleckiano. Significa acudir a la Historia conceptual no como a "una mera historia de conceptos", ${ }^{19}$ sino, en palabras de Koselleck como a "la doctrina de las condiciones de posibilidad de historias (Geschichten)", ${ }^{20}$ a una disciplina teórico-histórica de pleno derecho, inmersa en una transdisciplinaridad en la cual inyecta historicidad a las otras ciencias humanas y sociales. ${ }^{21}$ Agreguemos, para el propósito de estas páginas: acudir a una disciplina que hará de cada país o mundo su objeto directo, y de cada lengua su lengua, en otras palabras desplazamos el problema de la traducción "de Europa a la 'no-Europa'", hacia un segundo plano y privilegiamos en cambio la mirada de la "no-Europa" hacia Europa. Quizás encontremos los conceptos europeo-occidentales, moderno-contemporáneos, pero será en una etapa avanzada o al final de la investigación, y ya con otro estatuto respecto del pensamiento "no-europeo". Lo que me parece erróneo es partir a la búsqueda de Europa en la no-Europa. Evitemos malentendidos: no invertimos la mirada para reemplazar un centro por otro, sino para reconstruir lo común de la humanidad en una historia descentralizada, respetuosa de la igualdad de los pueblos. Que el investigador sea nativo de esas tierras extrañas o extranjero, existe una condición esencial, sobre la que Duso ha insistido, y que consiste en abordar ese Otro cultural o temporal con clara conciencia de la semántica de nuestros conceptos moderno-contemporáneos: sin esa conciencia, la extrapolación espontánea de sentido acecha a la investigación como una trampa letal.

En la elucidación del concepto Estado en tierras extrañas, el papel decisivo de la teoría y de la conciencia de la semántica de los conceptos que son contemporáneos al investigador es transparente, mientras que sin esa conciencia la mejor erudición puede sin embargo desembocar en una interpretación aporética y errónea.

El empleo recurrente de estos los conceptos "Estado" y "sociedad" para estudiar todas las épocas, aun las más lejanas, y a la vez la escasez o incluso la ausencia de conciencia crítica sobre la contemporaneidad de estos conceptos, les

\footnotetext{
${ }^{18}$ VILLACAÑAS, José Luis “Introducción”, en KOSELLECK, Reinhardt Esbozos Teóricos. ¿Sigue teniendo utilidad la Historia?, Escolar y Mayo, Madrid, 2013, p.10.

${ }^{19}$ PALTI, Elías “Ideas, conceptos, metáforas. La tradición alemana de historia intelectual y el complejo entramado del lenguaje", en FERNÁNDEZ SEBASTIÁN, Javier y CAPELLÁN DE MIGUEL, Gonzalo (ed) Lenguaje, tiempo y modernidad. Ensayos de historia conceptual, Globo Editores, Santiago de Chile, 2011, p. 223.

${ }^{20}$ KOSELLECK, Reinhart "Histórica y hermenéutica", en KOSELLECK, Reinhart y GADAMER, Hans-Georg Historia y Hermenéutica, Paidós, Barcelona, 1997, p. 70.

21 Ver los capítulos 2 ("¿Sigue teniendo utilidad la Historia?") y 3 ("Investigación interdisciplinar e Historia") en KOSELLECK, Reinhart Esbozos Teóricos..., cit., así como la "Introducción" de José L. Villacañas.
} 
ha otorgado espontáneamente un estatuto casi meta-histórico de neutralidad y de extraterritorialidad en la investigación e interpretación del pasado. ${ }^{22}$ Sin embargo, este paradigma posee, como los vinos y los quesos de Francia, una "denominación de origen controlada": es tributario de una realidad política precisa, la de la primera mitad del siglo XIX en Europa Occidental. ${ }^{23}$ Lejos de ser neutro, su manejo produce efectos sobre la elección, el tratamiento y la interpretación de las fuentes. Empero, la perdurabilidad del paradigma así como el uso irreflexivo del concepto "Estado", ${ }^{24}$ han terminado por correr un velo frente a su contexto original, que oculta que este paradigma y sus conceptos están datados, tanto histórica como teóricamente. ${ }^{25}$ Caracterizado por el rechazo explícito a reflexionar sobre su bagaje conceptual, esta historiografía erige el anacronismo en modelo. ${ }^{26}$

La segunda parte de este texto levantará ese velo para echar luz sobre lo que los arquitectos llaman un "vicio oculto" de la construcción: el paradigma somete la lectura de las fuentes a premisas teóricas aceptadas en el siglo XIX, pero desde hace tiempo incompatibles con los logros de las ciencias humanas y sociales. Espero poder demostrar igualmente que un trabajo crítico sobre el concepto "Estado" empleado por la historiografía rusa vuelve evidentes las tensiones entre el empleo de este concepto y el material empírico aportado por esa misma historiografía. No hay en este último objetivo ninguna pretensión

\footnotetext{
22 Escribir "todas las épocas" no es una exageración. Por ejemplo, el "Estado" habría sido una novedad fundamental a fines del III milenio A.C. C; FOREST, Jean-Daniel Mésopotamie, l'apparition de l'Etat, VIIe-IIle millénaire, Jaca Book, Milán, 1996, pp. 241-244. Citado por HUOT, Jean-Louis "Vers l'apparition de l'Etat en Mésopotamie. Bilan des recherches récentes", Annales, Histoire, Sciences Sociales, 2005, 5, en página 973: "Durante estos cuatro mil años (desde el fin del S.VII al fin del III milenio), hemos pasado en este país de un tejido liviano de comunidades aldeanas a un Estado en el sentido moderno del término. El período que nos interesa está a caballo entre la prehistoria y la historia."

23 Utilizo la palabra "occidental" por comodidad, sin ignorar la heterogeneidad de las construcciones políticas en Europa y otros lugares.

24 Recientemente, un helenista escribió, "los historiadores definen muy raramente sus conceptos" y señaló que el término estado es usado en un sentido extremamente amplio a propósito de cualquier comunidad política con un alto nivel de organización; HANSEN, Mogens Polis and City-State. An Aancient Concept and its Modern Equivalent, Acts of the Copenhagen Polis Centre, vol. 5, Historisk-filosofiske Meddelelser 76, The Royal Danish Academy of Sciences and Letters, Munksgaard, Copenhagen, 1998, p. 35.

${ }^{25}$ Este artículo trata sólo sobre el Estado. El estudio del uso historiográfico del otro concepto fundamental del paradigma -la sociedad- merece una investigación específica. Acerca de la ausencia de la sociedad civil en Rusia, al menos antes de la segunda mitad del s.XIX, y para un modo eficaz de llevar a cabo este debate, ver WIRTSCHAFTER, Elise "A State in Search of a People: The Problem of Civil Society in Imperial Russia", in BARTLETT, R. - LEHMANNCARLI G. Eighteenth-Century Russia: Society, Culture, Economy, Papers from the VII International Conference of the Study Group on Eighteenth-Century Russia, Wittenberg, 2004, Berlin, 2007, pp. 373-381.

${ }^{26}$ Se ha afirmado recientemente que "el uso frecuente de un lenguaje anacrónico para nombrar los (...) elementos del poder del Estado: información, propaganda, burocracia, política económica..." es un "procedimiento fecundo (...) que afirma de entrada la modernidad del Estado" en los siglos XIV y XV, CARBONELL, Charles-Olivier "Les origines de l'Etat moderne: les traditions historiographiques françaises (1820-1990)", en BLOCKMANS, Wim y GENET, Jean-Philippe (eds.) Visions sur le Développement des Etats modernes, Ecole française de Rome, "Collection de l'Ecole française de Rome, v. 171", Roma, 1993, p. 311, subrayado mío. Ver también MONSALVO ANTON, José La Baja Edad Media en los siglos XIV-XV. Política y Cultura, Síntesis, Madrid, 2000. El título del capítulo 3 es “Ideas y representaciones políticas sobre el rey, la corona y el reino (el caso castellano)". Sin embargo el autor, eminente especialista del Medioevo español, advierte que "ha preferido no entrar en digresiones conceptuales y renuncia a las "definiciones detalladas y teóricas" de los conceptos que emplea, tales como "política, cultura, poder, estado, sociedad política, etc.", p. 13.
} 
nominalista. No intento definir al Estado para luego confrontar lo que conocemos de la historia rusa a esa definición y así verificar si ambas concuerdan o no. La lógica de mi pensamiento es otra. En la medida en que la tradición historiográfica identifica muy a menudo en el sistema político moscovita (siglo XV a principios del XVIII) un "Estado", y en la Rusia "peterburguesa" (principios del siglo XVIII a 1917) un "Estado abstracto y despersonalizado", también llamado "Moderno", se tratará de establecer si hay isomorfismo, o al contrario heterogeneidad entre lo que, por una parte, la misma historiografía nos enseña sobre el antiguo régimen ruso, y por otra parte, los rasgos que ella le atribuye al concepto "Estado".

En la tercera y última parte, se expone una distorsión cognitiva inherente al uso acrítico del concepto "Estado". El objetivo no es exponer un error, todos los investigadores podemos cometerlos, sino poner en evidencia cómo ese uso conduce a conclusiones erróneas. En otras palabras, designo aquí bajo la fórmula "distorsión cognitiva" un razonamiento que orientado por ese uso acrítico se va alejando cada vez más de las fuentes hasta elaborar conclusiones que ya no solo no guardan ningún lazo con las fuentes sino que están en contradicción con lo que en estas últimas se puede leer.

\section{El paradigma "estatalista"}

\section{Una construcción teleológica occidental}

La visión de la historia de un país, a la vez como un state-building process y como la evolución de las relaciones entre el Estado y la sociedad nació durante la primera mitad del siglo XIX, en Europa occidental. Esta visión, brillantemente teorizada por Hegel, correspondía a una situación política dominada por la construcción y/o la consolidación del Estado liberal, en el contradictorio proceso iniciado en 1789. Si bien no todos los historiadores de la época dirigían, como Guizot, un gobierno, muchos de ellos se comprometieron con la política y tuvieron responsabilidades en el Parlamento o en otras instancias de gobierno. En esas condiciones se plasmó la fórmula "Estado moderno" ("moderne staat") que según Stephen Skalweit, aparece en el pensamiento alemán entre 1830 y 1840, para referirse ante todo al "Estado constitucional". ${ }^{27}$ El presente era el apogeo de la historia. Para demostrarlo, los historiadores describieron un pasado en el que aislaron de sus estructuras originarias numerosos factores y los alinearon teleológicamente, para presentarlos como antecedentes del Estado, como si los actos del pasado hubieran tenido la intención de producir lo que tuvo lugar más tarde. El camino entre la modernidad temprana y la Época contemporánea fue concebido como evolutivo. La revolución ya no era necesaria. Resultaba así una historia acumulativa de "precedentes históricos" que justificaba el presente como resultante del pasado. La historia se realizaba en Occidente y culminaba en el Estado. ${ }^{28}$ Los intelectuales originarios de los países situados en los márgenes de Occidente pudieron leer en su filósofo preferido que en "la historia mundial solo son conocidos aquellos pueblos que forman un Estado". ${ }^{29}$

\footnotetext{
27 SKALWEIT, Stephan Der "moderne Staat". Ein historischer Begriff und seine Problematik, Rheinisch-Westfälische Akademie der Wissenschaften, Vorträge G 203, Opladen, 1975, pp. 17-18. ${ }^{28}$ IGGERS, Georges The German Conception of History, University Press of New England, Revised edition, 1988 [1968].
} 


\section{El paradigma en Rusia: el concepto de Estado (Gosudarstvo)}

Ese paradigma occidental fue introducido en Rusia por "la escuela estatalista", llamada también "jurídica": Serguei Solovev (1820-1879), Constantin Kavelin (1818-1885) y Boris Chicherin (1828-1904) en primer lugar. ${ }^{30}$ Desde entonces, la gran mayoría de las investigaciones se insertó en este paradigma. ${ }^{31}$ El lugar de Hegel en la concepción que los fundadores de la escuela tenían del Estado, es conocido. $^{32}$ Siguiendo a Hegel, Chicherin afirma que el estado se sitúa por encima de los intereses particulares de los estamentos sociales y del egoísmo del homo economicus. ${ }^{33}$ El Estado existe si puede ser claramente diferenciado de la sociedad civil; es la realización última de la libertad y de los derechos del individuo. $^{34}$ Para Chicherin, no hay Estado allí donde una parte de los habitantes se somete, según contratos puntuales, respecto de otra parte; es decir, allí donde las formas de dominación no son las definidas por el Derecho contemporáneo. Hay Estado si todos los ciudadanos se someten a leyes generales y si estas leyes no cambian con cada situación particular, según la región y los actores en juego. El sistema político estatal supone una sociedad consciente de su unidad social y no un conglomerado compuesto por individuos definidos por su dignidad heredada al nacer. El Estado es un poder

\footnotetext{
${ }^{29}$ HEGEL, Georg Wilhelm The Philosophy of History, trans. SIBREE, J. Dover Books, New York, 1956, p. 39. Para una reciente actualización del tema "Hegel et la Russie" ver SILJAK, Ana "Between East and West: Hegel and the origins of the Russian dilemma", Journal of the History of Ideas, 62 (2), 2001, pp. 335-358.

${ }^{30}$ Antes de estos historiadores, el término gosudarstvo ya había sido objeto de polémicas, pero era usado en el sentido de poder centralizado y de territorio independiente. Para Polevoi, el gosudarstvo solo existe después del yugo mogol y por eso titula su obra Istoriia Russkogo naroda (Historia del pueblo ruso), contra Karamzin, cuya famosa obra portaba como título Istoriia Russkogo gosudarstva (Historia del estado ruso). Ver MILIUKOV, Paul Glavnye techeniia russkoi istoricheskoi mysli (Las corrientes principales del pensamiento histórico ruso), 1913, pp. 301-302. Kavelin reprocha a Pogodin y Karamzin una historia política superficial del gosudarstoo ignorando su estructura interna y la confusión, en Pogodin, entre política e historia, lo que hacía de esta un garante del orden actual; KAVELIN, Constantin "Istoricheskie trudy M.P.Pogodina" (Los trabajos históricos de Pogodin), en Sobranie Sochinenii (Obras Completas), t. 1, 1897, pp. 231-235. Sobre las relaciones entre Karamzin y la escuela estatal, BLACK, Joseph L. "The "State School" Interpretation of Rusian History: a Re-Apraisal of Its Genetic Origins", Jahrbücher für Geschichte Osteuropas, Band 21, Heft 4, 1973, pp. 509-530.

${ }^{31}$ Sobre la actualidad de la escuela, ver entre otros: KITAEV, V.A. Ot Frondy k oxranitel'stou. Is istorii russkoii liberal'noi mysli 50-60x godov XIX veka, (De la Fronda a la defensa del orden. Sobre la historia del pensamiento liberal ruso de los años 1850-1860), Moscú, 1972; “Gosudarstvennaia shkola v russkoi istoriografii: vremia pereotscenki?" (La Escuela estatalista en la historiografía rusa: ¿llegó el momento de su reevaluación?), Voprosy Istorii, 3, 1995, pp. 161-164; BEYERLY, Elizabeth The Europecentric historiography of Russia, Mouton, Paris, 1973; KOLLMANN, Nancy Kinship and Politics. The Making of the Muscovite Political System, 1345-1547, Univeristy Press, Stanford, 1987, pp. 9-11; KIVELSON, Valerie Autocracy in the Provinces. The Muscovite Gentry and Political Culture in the Seventeenth Century, University Press, Stanford, 1996, p. XV; BUSHKOVITCH, Paul Peter the Great. The Struggle for Power, 1671-1725, University Press, Cambridge, 2001, pp. 1-2.

${ }^{32}$ MEDUSHEVSKII, Andrei “Gegel' i gosudarstvennaia shkola russkoi istoriografii " (Hegel y la escuela estatalista de la historiografía rusa), Voprosy Filosofii, 1988 (3), pp. 103-115.

${ }^{33}$ HAMBURG, Gary M. Boris Chicherin and Early Russian Liberalism 1828-1866, University press, Stanford, 1992, p. 101.

${ }^{34}$ El curso que Chicherin dictó sobre Hegel en la Universidad permite ver qué elementos de la Philosophie du Droit de Hegel el historiador privilegiaba y cómo los presentaba (en particular los $\S$ 182-262). Ver: CHICHERIN, Boris Istoriia Politicheskij Uchenii, (Historia de las doctrinas políticas) t.4, Moscú, 1877, pp. 573-609.
} 
superior que se ubica por encima de los poderosos y de los débiles. Cada interés particular está sometido al interés general encarnado en el Estado. ${ }^{35}$

\section{En busca del Estado ruso}

La historia política supone, para ser llevada a la práctica, la identificación de un dominio político autónomo. Ahora bien; puesto que el concepto y la realidad histórica "Estado" fueron las resultantes de la autonomización de la política en Occidente, la proyección del concepto "política" a Rusia plantea más preguntas de las puede resolver: ¿en qué momento se puede datar en Rusia este proceso de emancipación de la esfera política?

\section{a) Las premisas del paradigma}

Apenas la historia acababa de convertirse en una disciplina en Rusia, cuando sus profesionales salieron en busca del pasado del Estado ruso, armados de un concepto/categoría de análisis prestado - "Estado"- que sintetizaba una estructura histórica radicalmente nueva en Occidente, construida contra el Antiguo Régimen (pensemos en la soberanía del pueblo contra la del rey, entre otras). En las fuentes, encontraron por todas partes la palabra gosudarstvo. No ignoraban sus significados en la Rusia moscovita. ${ }^{36}$ Conocían la diferencia radical entre los significados de esta palabra en las fuentes y la del concepto gosudarstvo que les servía de categoría de análisis. En esta palabra, percibían una idea que poseía un núcleo de sentido permanente, pero que evolucionaba en el tiempo y reflejaba de ese modo la evolución de las cosas. El investigador debía reconstruir esta evolución, la que a su vez confirmaba la validez de la palabra para todo el período transcurrido desde la centralización definitiva de los principados rusos alrededor de Moscú (siglos XV-XVI). La antigua palabra y el concepto del siglo XIX se confundían, lo que volvía reales los riesgos de leer la primera prestándole los significados del segundo. Al mismo tiempo, los historiadores de la "escuela estatal" sabían que la Rusia de su época, con la servidumbre (abolida solo en 1861), sin libertades y jurídicamente fragmentada en estamentos (hasta febrero de 1917), ignoraba prácticamente todos los

\footnotetext{
${ }^{35}$ CHICHERIN, Boris Dujovnye i dogovornye gramoty velikij i udel'nyj knjazei, in Opyty po istorii russkogo prava, (Los testamentos y los tratados contractuales de los grandes príncipes y de los príncipes de tierras patrimoniales), Moscú, 1858, pp. 234-236 y 369; "Promyshlennost' i gosudarstvo v Anglii " (La industria y el estado en Inglaterra), Ateneia, 12, 1858, p. 213, citado en KITAEV, Ot Frondy, 100. Ver también: SKINNER, Quentin "From the state of princes to the person of sate", in Visions of Politics, vol. 2, Renaissance Virtues, Cambridge University Press, Cambridge, 2002, pp. 386, n.236, 407, 409-410 y 413.

36 Recordemos que gosudarstvo -cuya primera forma fue gospodarstvo- se empleaba en dos sentidos: la dignidad del gosudar' (dominus, el dueño, el amo), ya sea el Gran Príncipe primeramente y enseguida el Zar y las tierras que le pertenecen. Designa un territorio según el modelo del polaco panstwo que calcaba las palabras latinas dominum et dominatio, ver ANDRÁS, Zoltan Fejezetek az orosz szókincs történetébõl (Sobre la historia del léxico ruso), Budapest, 1987. Es también el poder del gosudar' sobre lo que le pertenecía, de allí su sentido de "gobierno (pravlenie)" y las posesiones del gosudar', ante todo las tierras y los que las habitaban; TOLSTIKOV, A.V. "Predstavleniia o Gosudare i Gosudarstve v Rossii vtoroi poloviny XVI pervoi poloviny XVII veka" (Las representaciones del Gosudar y del Gosudarstvo en la Rusia de la segunda mitad del siglo XVI - primera mitad del XVII), Odissei, Nauka, Moscú, 2002, p. 296. También podía significar el "trono", KROM, M. "Rozhdenie "gosudarstva" : iz istorii moskovskogo politicheskogo diskursa XVI v" (El nacimiento del "gosudarstvo": sobre la historia del discurso político moscovita del siglo XVI), en KOPOSOV, N. (ed.) Istoricheskie poniatiia i politicheskie idei v Rossii XVI-XX veka, (Los conceptos históricos y las ideas políticas en la Rusia de los siglos XVI-XX), Aletheia, San Petersburgo, 2006, pp. 60-61.
} 
componentes de la estructura histórica sintetizada en el concepto Estado. ¿Por qué, sin embargo, intentaron reconstituir la historia rusa a través de la historia del Estado ${ }^{37}$ Porque la investigación estaba orientada por las premisas del paradigma que demostraron una real capacidad para producir efectos en la interpretación. Si estos historiadores interpretaron la historia de Rusia a través de la construcción del Estado, fue porque daban por sentado que Rusia seguía, con retraso, a Occidente. Su referencia era "el sistema inglés basado en el respeto al Derecho" y el "pensamiento del Estado en Francia". ${ }^{38}$ A este respecto, la posible alteridad fue excluida de inmediato: era suficiente concebir que Rusia seguía el camino de Occidente para concluir que la autocracia no era, por ejemplo, un "despotismo oriental", como pensaban los "europeos occidentales". ${ }^{39}$ Puesto que "el Estado que avanza sin desviarse del camino predeterminado", es la realización de la Historia, estos historiadores adaptaron el pasado en función de este telos: "el desarrollo del Estado era la tarea principal de la antigua Rusia". ${ }^{40}$ He ahí las tres premisas del paradigma state-society fácilmente perceptibles: el eurocentrismo, el evolucionismo y la teleología.

\section{b) La tensión entre el concepto "Estado" y las fuentes}

Según Kavelin ya en el s. XV, se constata "la aparición del Estado (gosudarstvo)" y existe une "esfera estatal (gosudarstvennaia)". El relato pendula entonces entre un Estado ya presente y un proceso de construcción del Estado. Como no recordar las palabras de un historiador del Derecho: "Es algo, el Estado, literalmente preconcebido. Ya es su epifanía, y no su historia la que resulta." 41 La sociedad y el Estado ya están ahí, previamente, inherentes a Moscovia, solo que van a completarse con formas nuevas. ${ }^{42}$ Las contradicciones de esta lógica eran inevitables. El Estado y la sociedad son datos a priori cuyo "sentido profundo" en Rusia sería el isomorfismo entre lo privado y lo político. ${ }^{43}$ Sin embargo, esta distinción era subrayada en otros textos surgidos de la misma escuela como uno de los rasgos distintivos del Estado! ${ }^{44}$ El Estado existía ya, pero "la idea del Estado" era no solo "casi invisible bajo las formas antiguas y establecidas", es decir, bajo el orden de los clanes y la relación "propiedadamo", sino también "impregnada por estas últimas". ${ }^{45}$ Esta situación

\footnotetext{
${ }^{37}$ Hay divergencias entre estos historiadores. Pero en la medida en que ellos comparten las premisas del paradigma, no haré referencia a ellas.

38 CHICHERIN, Boris “O razvitii drevne-russkoi administratsii” (Rech', proiznesennaia pri publichnom zashchishchenii dissertatsii “Ob oblastnyj uchrezhdenjaj Rossii v XVII veke (Sobre las instituciones regionales de la Rusia en el siglo XVII), en Opyty po istorii russkogo prava, (Ensayos sobre la historia del derecho ruso), Moscú, 1858, p. 385.

39 KAVELIN, Constantin Vzgliad na iuridicheskii byt' drevnei Rossii, (Observaciones sobre la situación jurídica de la Rusia antigua), en Sobranie Sochinenii (Obras Completas), t. 1, 1848, pp. 637-638.

${ }^{40}$ CHICHERIN, Boris “O razvitii drevne-russkoi administratsii”, cit., pp. 386, 377 y 380-381.

${ }^{41}$ Estas palabras, escritas a propósito de la historiografía tradicional del "Estado Moderno" en Occidente, caracterizan el paradigma globalmente: CLAVERO, Bartolomé "De un estado, el de Osuna, y un concepto, el de Estado", Anuario de Historia del derecho español, t. 57, Madrid, 1987, p. 963.

42 KAVELIN, Constantin "Mysli i zametki o russkoi istorii” (Notas e ideas sobre la historia rusa), 1866, in Sobranie Sochineni, 651-2.

${ }^{43}$ KAVELIN, Constantin "Mysli i zametki o russkoi istorii", cit., p. 637.

${ }^{44}$ CHICHERIN, Boris Dujovnye i dogovornye..., cit., p. 234.

${ }^{45}$ El término ruso que traduzco como propiedad es votchina y designaba un dominio, propiedad del señor (Gran príncipe, zar o nobleza antigua como los boyardos). El pomest'e era la tierra que
} 
permaneció vigente por más de doscientos años, hasta el siglo XVIII de Pedro el Grande, durante los cuales el pasado sufrió un fuerte sacudón pero no fue destruido. ${ }^{46}$ De hecho, cuando se detiene sobre el siglo XVII, Kavelin habla de "Estado" (en el sentido del concepto occidental contemporáneo), pero demuestra, a la vez, que nadie en aquélla época podía representarse este Estado y que lo que se entendía entonces era el godusarstvo como dominio-del-amo. ${ }^{47}$ De este modo, guiado por su instinto profesional, Kavelin describe para el siglo XVII un sistema respecto del cual el Estado es una institución ajena y no una especie de estadio superior. Sin embargo, dado que las transformaciones de Pedro el Grande iban a llegar a principios del siglo XVIII, Kavelin organiza retrospectivamente los materiales del pasado: "Bajo la votchina del Gran Príncipe se transparenta el Estado [...]; en el Estado moscovita, bajo las antiguas formas ya se desenvuelve un contenido nuevo". ${ }^{48}$ Este "contenido nuevo" se encarnará en Pedro y en su obra, abriendo una época de transformaciones que acaba de terminar, concluye Kavelin en 1846.

La tensión es evidente entre los significados inscriptos en el concepto de Estado que preside el análisis y la descripción de un sistema -la monarquía moscovita- que le es ajeno. Kavelin trata de resolverla desmembrando el sistema: relega ciertos elementos de Moscovia al rango de vestigios en vías de desaparición mientras eleva otros a la dignidad de embriones de un Estado en desarrollo. El historiador reconstruye lo que él cree que era una anticipación del futuro. En realidad, la tensión revela una dificultad para conceptualizar la alteridad del pasado, una especie de carencia analítica ocultada por el uso en un sentido común de las palabras Estado y sociedad. A pesar de todo, la resistencia de ese excelente investigador que era Kavelin respecto del carácter apriorístico de su interpretación atraviesa el texto, a espaldas del autor, allí donde el predicado debilita el sujeto: "A fines del siglo XVII, el Estado (Gosudarstvo) moscovita se encontraba en una situación anormal".$^{49}$ Esta tensión es constante: la investigación reconstituye un sistema ajeno a aquél que está inscripto en el concepto "Estado", en tanto que las premisas teóricas imponen el manejo retrospectivo de este último.

Pero esta tensión solo es perceptible si el lector tiene conciencia de la distinción entre las estructuras históricas sintetizadas por el concepto Gosudarstvo propio del paradigma y las realidades significadas por la palabra gusudarstvo en el pasado.

En resumen: los autores del relato teleológico afirman la presencia del Estado desde el siglo XV. Desechan lo que consideran que no va en el sentido de la Historia, reduciéndolo al estatuto de vestigios en vías de desaparición. Aceptan de cada época lo que consideran que anuncia el futuro, o sea desnaturalizan, puesto que los aíslan de su sistema, los factores que se van agregando progresivamente, unos a otros, en una acumulación producida por la visión evolucionista. Suponen que estos factores adquieren su madurez

\footnotetext{
la nobleza (dvoriane: de la palabra dvor, la corte) más reciente, recibía en usufructo a cambio del servicio al monarca. La distinción entre los dos tipos de posesión fue eliminada en el s. XVIII. La palabra "amo" era una de las principales significaciones de gosudar' (por ejemplo en la formula "amo de sus esclavos"). La relación votchina - gosudar' se refiere entonces a la dimensión patrimonial del poder en Moscovia.

${ }^{46}$ KAVELIN, Constantin Vzgliad na iuridicheskii..., cit., p.45.

${ }^{47}$ KAVELIN, Constantin "Mysli i zametki o russkoi istorii", cit., pp. 636-637.

${ }^{48}$ KAVELIN, Constantin Vzgliad na iuridicheskii..., cit., p. 46.

${ }^{49}$ KAVELIN, Constantin "Mysli i zametki o russkoi istorii”, cit., p. 651.
} 
constituyéndose en Estado bajo Nicolás I (1825-1855). En la tensión entre el saber concreto del historiador y las premisas de su razonamiento, estas dominan en el momento de la conceptualización. La idea misma de la alteridad no existe.

\section{El paradigma se resquebraja}

Quizá porque Chicherin era ante todo un historiador del Derecho, o porque tomó a su cargo explicar y enseñar lo que se entendía por Estado en los círculos eruditos occidentales, o quizá porque su apego al liberalismo suponía no pasar por alto la libertad como factor constitutivo del Estado, o probablemente por todos estos elementos juntos, a los cuales se agrega su sensibilidad por las fuentes, lo cierto es que la tensión entre estas y las premisas del paradigma encuentra en él una salida distinta a la de Kavelin, haciendo de este fundador del paradigma estatal uno de sus primeros sepultureros. Me parece que sobre este último punto no se le ha hecho justicia.

A través de sus trabajos, Chicherin puso el acento sobre la diferencia entre el poder ilimitado que se atribuía el zar y la realidad, en la que demasiadas cosas escapaban de sus manos, una realidad donde las medidas de la monarquía destinadas a corregir la desorganización, la corrupción y ciertas injusticias no daban frutos. ${ }^{50}$ Chicherin demostró que ni el poder central ni las administraciones locales cubrían la extensión del territorio que reivindican, que la administración y el derecho no estaban uniformizados, y que coexistían instituciones contradictorias. ${ }^{51}$ En el siglo XVII, los medios antiguos de la gestión del país se acumulaban con los nuevos, las relaciones entre las instituciones y sus empleados no estaban regidas por una norma única, sino caso por caso, trayendo en consecuencia la desigualdad en la administración de las regiones. La constatación fue inapelable: "Cuando un Estado desarrollado instaura un orden social, ubica en el mismo plano todos los fenómenos de la vida social reduciéndolos a categorías generales, definidas por las necesidades estatales. Pero tales categorías generales (...) no existían en el gosudarstvo moscovita." ${ }^{2} \mathrm{Su}$ conclusión es lógica: "en la administración regional del gosudarstvo moscovita se observa (...) la ausencia de un sistema estatal". ${ }^{53}$ Aquí, el sustantivo gosudarstoo parece reenviar a su significado en la antigua Rusia, mientras que el adjetivo "estatal" gosudarstvennii parece corresponder a los atributos del concepto contemporáneo del historiador.

Sin embargo, Chicherin se mantiene en un enfoque teleológico, pensando la situación desde el punto de vista de "la insuficiencia" 54 de un Estado que un día será "desarrollado". Pero señala sin ambigüedad la radical diferencia entre la Moscovia patrimonial donde las relaciones políticas se asientan, según él, en las relaciones privadas, y un sistema contemporáneo donde la existencia de una sociedad que se concibe como tal hace posible la existencia del Estado. ${ }^{55}$ Esta diferencia supera parcialmente las premisas del paradigma, sin eliminarlas, ya que Chicherin ve el Estado como el momento del apogeo de la Historia. Pero,

\footnotetext{
${ }^{50}$ CHICHERIN, Boris "O razvitii drevne-russkoi admnistratsii”, cit., pp. 383-385.

${ }^{51}$ CHICHERIN, Boris Oblastnye Uchrezhdeniia Rossii v XVII veke, (Las instituciones regionales rusas en el siglo XVIII), in Opyty po istorii russkogo prava, pp. 577-578.

${ }^{52}$ CHICHERIN, Boris Oblastnye Uchrezhdeniia Rossii v XVII veke, cit., p. 579.

${ }^{53}$ CHICHERIN, Boris Oblastnye Uchrezhdeniia Rossii v XVII veke, cit., p. 585

${ }^{54}$ CHICHERIN, Boris "O razvitii drevne-russkoi administratsii", cit., p. 385.

${ }^{55}$ CHICHERIN, Boris Dujovnye i dogovornye gramoty, cit., p. 236.
} 
gracias a esa diferencia, se resuelve la tensión entre estas premisas y la erudición, a favor de esta. En efecto, en un manuscrito de 1878, publicado recién en 1906, Chicherin estima que el fracaso para instaurar la "monarquía constitucional" determina por el momento el fracaso del Estado, esta "nueva construcción cuyo logro natural es la libertad política". ${ }^{56}$ Permanece optimista pues considera posible que el emperador "llame a sus súbditos a participar en la administración estatal" pero el único medio para garantizar esta participación, es instaurar, aun limitada, la participación popular. ${ }^{57}$ Para el Chicherin de 1878, Rusia no es todavía un Estado. Lo que le falta para serlo no es la modernización técnica de su gobernabilidad, sino dos rasgos esenciales de la modernidad política: la representación popular y la libertad política. ${ }^{58}$ En otros términos, un cuerpo institucional y jurídico distinto de la persona del zar y de sus súbditos no es todavía el Estado, aunque el objetivo proclamado sea la búsqueda del bien común. Faltan todavía las condiciones políticas para que el bien común sea definido democráticamente por el pueblo (el grado real de democracia es otro problema).$^{59}$ La despersonalización del poder es necesaria pero insuficiente para que el cuerpo institucional y jurídico se convierta en un Estado. Hace falta aún la soberanía popular. Lo que Chicherin sugiere es que la democracia es constitutiva del Estado, en tanto que este fue el resultado de la Revolución francesa. 56 CHICHERIN, Boris Konstitutsionnyi Vopros v Rossii. Rukopis' 1878, (La cuestión constitucional
en Rusia. Manuscrito de 1878), San Petersburgo, 1906, p. 9. La libertad política es para el liberal
Chicherin un factor sin el cual la la novedad histórica representada por el Estado no se hará
presente. Y, recíprocamente "Sólo en el Estado" pueden desarrollarse la libertad y la
personalidad, CHICHERIN, Boris Dujovnye $i$ dogovornye gramoty..., cit., p. 368. Es notable que
defienda lo contrario de Kavelin y en sus Memorias, considere a Nicolás $1^{\circ}$ y su gobierno
"despótico". Citado por HAMBURG, Gary Boris Chicherin..., cit., p. 95 .
57 CHICHERIN, Boris Konstitutsionnyi Vopros..., cit., pp. 9, 11, 33 y 26. Esta "representación" no
estaba seguramente en las intenciones de Alejandro II, y esto, bastante antes del terrorismo
antizarista practicado por el populismo revolucionario. En 1861, explicaba a Otto von Bismarck,
entonces ministro prusiano en Petersburgo que reporta sus palabras a Berlín: "La idea de recibir
consejo de mis súbditos, aparte de mis ministros no es en sí desaforada, una mayor
participación de notables respetados en los asuntos oficiales sería positiva. La dificultad, o más
bien la imposibilidad de realizar este principio reside en la experiencia de la historia, ya que no
ha sido nunca posible frenar el desarrollo liberal de un país en el límite que no hay que
pasar[...] Abdicar el poder absoluto encarnado en mi corona seria minar el aura de la autoridad
que domina la nación [...] Yo disminuiría la autoridad del gobierno in ninguna compensación si
tratase de permitir que los representantes de la nobleza o de la nación participen en el
gobierno", LIEVEN, Dominic Nicholas II. Twilight of the Empire, New York, 1996, p. 142.
58 Al

${ }^{58} \mathrm{Al}$ mismo tiempo, Chicherin afirma no percibir un personal político idóneo para actuar como personal del Estado, Konstitutsionnyi Vopros..., cit., pp. 27-29. Para evitar cualquier confusión, hay que tener en cuenta que lo que en el lenguaje común se llama "modernidad política" fue conquistada en la época contemporánea.

${ }^{59}$ La presencia de la fórmula "bien común" en el discurso ruso desde el s.17 ha confundido a los historiadores que lo han tomado como prueba de secularización y modernidad, olvidando las raíces religiosas y éticas, no políticas, de esta idea, así como la realidad detrás del discurso. La ausencia de una base sociológica y política para traducir esta fórmula en la realidad rusa es recordada por KLEIMOLA, A.M. "Up Through Servitude: The changing Condition of the Muscovite Elite in the Sixteenth and Seventeenth Centuries", Russian history / Histoire Russe, 6, Pt 2 (1979), p. 229 y por LEDONNE, John Ruling Russia. Politics and Administration in the Age of Absolutism 1762-1796, Princeton, 1984, pp. 12-17 and Absolutism and the Ruling Class: the Formation of the Russian Political Order, 1700-1825, Oxford University Press, 1991, p. 350. A propósito del discurso del poder, Kharkhordin puso el punto sobre la "i". Comentando On the Truth of the Monarch's Will de Feofan Prokopovich, uno de los ideólogos oficiales de Pedro el Grande escribió que: "La voluntad autocrática era la fuerza motriz del estado ruso y no importa cuánto se haya hablado sobre el bien público al cual el zar y el pueblo aspiraban, fue por orden del gosudar', señor absoluto de su dominio, que se implanto la 'patria' común", Main Concepts, pp. 14-15. 


\section{La actualidad del paradigma y sus distorsiones cognitivas}

Este parágrafo reconstruye el destino de una afirmación del historiador Serguei Solovev sobre los efectos de la aparición del Estado en las nuevas costumbres gubernamentales introducidas por Pedro, y en consecuencia, en las representaciones colectivas del poder. He elegido este ejemplo porque ilustra a la vez la continuidad historiográfica entre el comienzo de la escuela estatal y nuestros días, así como la influencia del paradigma en esa continuidad y la distorsión cognitiva inherente al uso no crítico del concepto Estado impuesto por este paradigma. Por distorsión cognitiva, entiendo el alejamiento progresivo del historiador respecto de las fuentes hasta la desaparición de todo lazo con ellas.

Según Solovev, "los rusos escucharon por primera vez bajo Pedro el Grande el verdadero ["nastoiashchoe", pero recordemos que la polisemia del término permite entenderlo también como "contemporáneo/ presente" C.S.N.I.] significado de gosudarstvo cuando debieron prestar juramento de fidelidad a él". ${ }^{60}$ Solovev no estaba lejos de la verdad. El 22 de febrero de 1711, Pedro instauró el Senado y nombró sus 9 miembros. Se preparaba en ese momento para partir a la campaña militar contra los turcos. Consciente de los peligros que corría, Pedro redacta el juramento que los senadores, llamados a dirigir el Imperio durante su ausencia, deberían prestar. Es el único juramento, entre todos los que he encontrado, donde figura la fórmula "fidelidad al gosudarstvo": cada senador jura "fidelidad a mi Amo/Señor 61 y a todo el

\footnotetext{
${ }^{60}$ SOLOVEV, Sergei Istoriia Rossii s drevneishikh vremen, (Historia de Rusia desde la antigüedad), Moscú, 1963, kn. IX (t. 17-18), p. 546.

${ }^{61}$ Estamos tan acostumbrados a la traducción de Gosudar' por Soberano o por Monarca que el término Amo puede sorprender. No obstante, la etimología de gosudar' se remonta al viejo iraniano *wis "clan, casa", *wis-pati "jefe de clan" y *wis-ypura "hijo del clan o de la casa real, príncipe", au despótes en griego, y a dominus en latin. BENVENISTE, Émile Le Vocabulaire des institutions indo-européennes, Editions de Minuit, Paris, 1969, t. 1, pp. 88-91; CORNILLOT, Françoise "L'aube scythique du monde slave", Slovo, INALCO, Paris, 1994, núm. 14. La traducción "Amo" respeta también su lugar en el contexto discursivo y su empleo en las relaciones cotidianas de autoridad y sumisión. En el Lexicon pour voyageurs (1764) de la Académie de sciences, dominus est rendu par gosudar'; DE MADARIAGA, Isabel "Autocracy and Sovereignity", Canadian-American Slavic Studies, 1982, v.16, núm. 3-4, pp. 376-385. John Alexander ha reproducido las palabras gosudar' $i$ gouidaryna utilizadas en los juramentos por Master et Mistress respectivamente, en su traducción del libro de ANISIMOV, Eugenio The Reforms of Peter the Great. Progress through coercion in Russia, M.E.Sharpe, New York and London, 1993, p. 31. Ver también: BOGATYREV, Sergei The Souvereign and His Counsellors. Ritualised Cnsultations in Muscovite Political Culture, 1350s-1570s, Supolaisen Tiedeakatemina Toimituksia Annales Academiæ Scientaum Fennicæ, Sarja-ser. Humaniora, Helsinki, 2000, v. 307, p. 90; Gosudarynja fue traducido por Domina en la versión latina de la titulación de Catalina la Grande, ver Polnoe Sobranie Zakonov Rossiiskoi Imperii. Sobranie pervoe s 1649 po 12 dekabria 1825g., (Compilación completa de las leyes del Imperio ruso desde 1649 hasta el 12 de diciembre de 1825), San Petersburgo, 1830, t. 22. núm. 15982, p. 107, Abril 1784 (de ahora en adelante P.S.Z.). El historiador rumano Nicolaie Iorga (Histoire des Roumains et de la Romanité orientale, Academia Romana, Bucarest, 1940, vol. 5, passim) eligió en francés, el término "maître" para traducir la titulación de los gospodars moldavos. A partir del siglo XIV, gosudar' adquiere también un valor político (soberano), pero las fuentes certifican que el título podía ser entendido literalmente, en el sentido "Amo de los esclavos". Así, en 1477-1478, las élites de Novgorod recuerdan al gran príncipe moscovita Ivan III (1440-1505), que pretende tener sobre su ciudad los mismos derechos que tiene sobre Moscú, su dominio familiar, la diferencia entre la palabra gospodin ("señor" de servidores libres) que ellas aceptan emplear y las palabras gosudar' o gospodar" (Amo de servidores no libres) que se niegan a usar. La diferencia entre "Amo" y "Señor" se transforma en conflicto en Moscú, en 1533, a la muerte de Basilio III, cuando sus hermanos se niegan a llamar gosudar' a su hijo, el futuro Ivan IV y prefieren la palabra gospodin. SZEFTEL, Marc "The Title of the Muscovite Monarch up to the End of the Seventeenth
} 
Gosudarstvo", así como a lo que los "intereses de mi Amo/Señor y del gosudarstvo exigen". ${ }^{62}$ Pedro ha dado la razón de este juramento en su carnet personal: amedrentar a los senadores para impedirles robar de las cajas o dejarse corromper. ${ }^{63}$ Sabía con quien trabajaba: sobre 9 senadores, durante los primeros seis años de funcionamiento del Senado, 6 fueron llevados a la justicia por delitos graves, dos fueron sobreseídos. ${ }^{64}$ Dejando de lado el problema del significado de gosudarstvo para Pedro, me parece difícil, en vista de las condiciones de la época, sacar conclusiones como Solovev, en lo concerniente a la recepción por los rusos en general de este significado a partir de tal juramento. Teniendo en cuenta los nueve juramentos que encontré, prestados durante el reino de Pedro, se puede concluir que: 1 . No hay ningún juramento separado de lealtad al Gosudarstvo ; 2. En uno solo, en 1711, los nueve senadores juraron fidelidad al "gosudar" y al "gosudarstvo" pero al mismo tiempo y en la misma frase; 3. En todos los juramentos, se jura lealtad al Gosudar'; 4. La palabra Gosudarstvo está ausente en cuatro juramentos; ${ }^{65}$ 5. En cuatro otros juramentos, luego de la lealtad al gosudar' encontramos el deber de combatir los enemigos de los "territorios y del gosudarstvo de Su Majestad el Zar" y de servir

\footnotetext{
Century", Canadian-American Slavic Studies, 1979, núm. 1-2, p. 63; JOROSHKEVICH, A.L. "Istoricheskie sud'by belorusskij i ukrainskij zemel' v XIV - nachale XVI v." (El destino histórico de las tierras bielorrusas y ucranianas entre el siglo XIV y el principio del XVI), en PASHUTO, V.T. - FLORIA, B.N. - JOROSHKEVICH, A.L. (eds.) Drevnerusskoe nasledie $i$ istoricheskie sud'by vostochnogo slavianstva, (La herencia de la Rusia antigua y el destino de los eslavos orientales), Moscú, 1982, pp. 74-75.

${ }^{62}$ MAN'KOV A.G. (ed) Zakonodatel'stvo perioda stanovleniia absoliutizma, (La legislación durante el establecimiento del absolutismo), en CHISTIAKOV, O.I. (ed), Rossiiskoe Zakonodatel'stvo X-XX vekov, (La legislación rusa, siglos X-XX), t.4, Moscú, 1986, p. 157. Ver también: P.S.Z., t.4, p. 643, núm. 2329. Boris Mironov se apoya en esta última fuente para afirmar que "En 1711 Pedro I introdujo una nueva forma de juramento de fidelidad no solo al gosudar', como antes, sino tambien al gosudarstvo", MIRONOV, Boris Sotsial'naia istoriia Rossii, (Historia social de Rusia), t. 2, Dimitrii Bulanin, San Petersburgo, 1999, p.128. Ciertamente, el texto del juramento no precisa que esté destinado exclusivamente a los senadores. Sin embargo, está fechado el 2 marzo, el mismo día en que juraron los senadores. Todo indica que este juramento estaba destinado no a la administración en general, sino solo a los senadores. En Mironov, el verbo "vvel " que indujo a los traductores en inglés a escribir "Henceforth, subjects swore fealty not only to the tsar but also to the state" permite pensar que el juramento de 1711 fue, desde entonces, la norma: MIRONOV, Boris - EKLOF, Ben The Social History of Imperial Russia 1700-1917, v. 2, Westview press, Colorado, 2000, p. 14. Pero, hasta donde sé, nunca fue utilizado. Respecto al "interés del gosudarstvo", se ha señalado, con apoyo en las fuentes, que estaba definido en los marcos de la defensa de "los derechos y ventajas" de la autocracia; PLOTNIKOV, A.B. "Ogranichenie samoderzhaviia v Rossii v 1730 g.: idei i formy" (Los límites de la autocracia en la Rusia de 1730: ideas y formas), Voprosy Istorii, 2001, p. 1.

${ }^{63}$ ANISIMOV, E.A. Gosudarstvennye Preobrazovanija i samoderjavie Petre Velikogo v pervoi chetverti XVIII veka, (Las reformas estatales y la autocracia bajo Pedro el Grande en el primer cuarto del siglo XVIII), San Petersburgo, 1997, p. 30.

${ }^{64}$ PREOBRAJENSKIJ, A.A. - NOVICKAJA, T.E. (eds.) Zakonodatel'stvo Petra I, (La legislación de Pedro I), Moscú, 1997, Izdatel'stvo “Iuridicheskaia literatura”, p. 63.

65 P.S.Z., t.4, núm. 2267 (abril 1710, la Marina de Guerra). El juramento de la Administración general en: LEBED'EV V.I. (éd.) Reformy Petra I, (Las reformas de Pedro I), Moscú, 1937, pp. 109110. El juramento del jefe de la policía de Moscú en P.S.Z., t. 6, núm. 4047. El Manifiesto sobre la sucesión, en: LENTIN, Anthony Peter the Great. His law on the imperial succession in Russia, 1722. The official commentary, Headstart History, Witney, 1996, pp. 132-133.
} 
los intereses del gosudarstvo, ${ }^{66}$ 6. No hay, pues, ninguna sistematización en la inclusión de la fidelidad al Gosudarstvo. ${ }^{67}$

No obstante, los historiadores perdieron el rumbo. La frase de Solovev fue retomada poco después por otro de los grandes historiadores rusos, Vasili Kliuchevski, en la forma siguiente: "gracias a la instauración del juramento de fidelidad ya no solo al gosudar', sino también al gosudarstvo, se ofreció al pueblo por primera vez la posibilidad de comprender el verdadero significado de gosudarstvo". Solovev había escrito "cuando (los rusos) debieron prestar juramento de fidelidad". Había precisado además que no se trataba de una situación "definitiva", puesto que tanto con Pedro como después de él, en la práctica, fue la costumbre de servir los individuos al poder, y no el gosudarstvo la que había triunfado. Pero al emplear la palabra "vvedeniem" que traduzco como "instauración", Kliuchevski introdujo una connotación normativa ausente en el texto de Solovev.

A continuación, Kliuchevski nos deja su propia interpretación: "Pedro distinguió (razdelil) estas dos nociones (gosudarstvo - gosudar') otorgando carácter de ley al acto de prestar juramento diferenciando al gosudar' y al gosudarstvo" ${ }^{68}$ Afirmando el carácter normativo del juramento, se alejó aún más de Solovev, pero sin indicar la fuente que supuestamente lo autorizaba a afirmar que Pedro hizo del juramento al gosudarstvo una norma.

Los historiadores occidentales a menudo han citado el libro de Kliuchevski sobre Pedro el Grande, pero en general a partir de traducciones. La frase rusa "Pedro distinguió (razdelil) estas dos nociones" estaba justificada puesto que Pedro hizo prestar juramento al gosudar' y al gosudarstvo, empero hay que precisar al interior del mismo juramento, y en mi conocimiento, en un solo juramento. La forma verbal razdeliat', significa ante todo "distinguir/ separar las partes (delit' na chasti)" del todo pero la distinción puede hacerse al interior de ese mismo todo. He traducido más arriba razdelno por "diferenciando". Ahora bien, las traducciones del libro de Kliuchevski en francés y en inglés le hacen decir lo que no ha dicho, y amplían la distorsión de la afirmación de Solovev. En la edición en francés, se lee "Pedro dividió estas nociones mediante una ley exigiendo juramentos separados para el Estado y el soberano" ("Pierre divisa ces notions par une loi exigeant des serments séparés pour l'Etat et pour le souverain"). ${ }^{69}$ La palabra "separados (séparés)" da al lector el derecho de pensar que se trata de dos juramentos diferentes. La versión inglesa es más explícita en este sentido: "Peter insistió en dos juramentos, uno al Estado, el otro al Monarca" ("Peter insisted on two oaths, one to the State, and one to the Monarch") ${ }^{70}$ Así el relato historiográfico pasó de jurar fidelidad al gosudar' y al gosudarstoo al interior de una misma frase en un mismo juramento a la afirmación de la existencia de dos tipos de juramento.

\footnotetext{
${ }^{66}$ El Estatuto de la Guerra (1716), en MAN'KOV A.G. (ed) Zakonodatel'stvo..., cit., p. 328. El juramento de los magistrados (1721), en P.S.Z., t. 6, núm. 3708. La Marina de guerra, en P.S.Z., t.4, núm. 2267. El juramento de los prisioneros suecos (1721) que quieren instalarse en Rusia en P.S.Z., t. 6, núm. 3778.

${ }^{67}$ Las líneas precedentes sintetizan un estudio más detallado de los juramentos y del significado de gosudarstvo en el siglo XVIII: INGERFLOM, Claudio "'Loyalty to the State' under Peter the Great? Return to the sources and the historicity of concepts", cit.

${ }^{68}$ KLIUCHEVSKII, Vasili Sochineniia $v$ deviati tomah, (Obras en 9 volúmenes) t. IV, Kurs russkoi istorii, Chast' IV, Mysl', Moscú, 1989, pp. 187-193.

${ }^{69}$ KLIOUTCHEVSKI, Vassili Pierre le Grand, Payot, Paris, 1991, pp. 248-249.

${ }^{70}$ KLYUCHEVSKY, Vasili Peter the Great, Beacon Press, London, 1984, p. 259.
} 
Al mismo tiempo, la traducción de gosudarstvo por État/State, termina de ocultar al lector de hoy la diferencia entre los significados de la palabra gosudarstvo en la época de Pedro y el del concepto Gosudarstvo que Solovev y Kliuchevski empleaban siguiendo la huella de la historiografía occidental. ${ }^{71} \mathrm{El}$ paso de uno a dos juramentos, así como la pérdida de significados de la palabra gosudarstvo, resultado de la confusión entre la palabra y el concepto, agravado a continuación por la traducción a lenguas extranjeras, fueron adoptados por la historiografía contemporánea. Se ha podido entonces afirmar que Pedro "rompió la identificación de la persona del zar con el Estado e insistió en que la población prestase dos juramentos separados, uno al monarca y otro al Estado". ${ }^{72}$ Esta tradición desembocó afirmaciones que despojan a las palabras del pasado y a los conceptos modernos de su historicidad propia y ya no guardan contacto con las fuentes, pero se repiten actualmente en los libros sobre la historia del Estado en Europa. ${ }^{73}$

\section{Conclusiones}

Acabamos de ver una serie de extravíos historiográficos sucesivos, producidos por la adhesión al paradigma y basados en la convicción de que el gosudarstvo

\footnotetext{
${ }^{71}$ En el siglo XVIII, el primer sentido de gosudarstvo es Imperio o Reino (zarstvo) o "pais" (strana). De acuerdo al texto del 27 de agosto de 1747, el juramento que los extranjeros tenias que prestar para ser sujetos del emperador ruso expresaba la fidelidad a Su Majestad Real y a los intereses del Gosudarstvo ruso. La traducción oficial al alemán hecha en la corte rusa decía: "Rusichen Reiche führen"; P.S.Z. t. 12, 749. Ver también el Manifiesto del 7 de noviembre de 1742 sobre la designación de Pedro III, donde el término goduarstvo está ausente, pero se encuentra "Imperio", P.S.Z., t.11, 8658. En esa época, los alemanes usaban el término Reich para referirse a su Imperio compuesto por miles de diferentes entidades como los Herrschaften, equivalentes a los gosudarstva (le pluriel de gosudarstoo) rusos, con sus príncipes particulares, o los Reichsstädte que eran ciudades-estados independientes. Agradezco al profesor Michael Stolleis por esta información. Gosudarstvo significaba también "una parte del país, una región particular, una provincia del Imperio ruso". Otro ejemplo, era común decir "en el gosudarstvo de Siberia", cf. KAFENGAUZ, B. Pis'ma i Bumagi imperatora Petra Velikogo, (Cartas y documentos del emperador Pedro el Grande), Moscú, 1952, t. IX, v.1, p. 291. Luego de una larga enumeración de los territorios de los cuales el monarca era simultáneamente autócrata, Zar y Gran Príncipe, el título oficial incluía "otros numerosos gosudarstva y tierras" de los cuales el era "heredero, amo (gosudar') y protector". Los gosudarstva eran partes del Zarstvo, las posesiones del Zar. En este sentido, la traducción por "estados" es correcta y fue utilizada por el propio Pedro en francés, LENTIN, Anthony Peter the Great. His law on the imperial succession in Russia, 1722, nota a pie núm. 28 , p. 285. El uso de "estados" para las partes de un reino no es específicamente ruso. El embajador de Hanover en San Petersburgo, Friedrich Christian Weber, escribió sobre la nueva política de Pedro concernía "ses états et pour humaniser son people". BUSHKOVITCH, Vassili Peter the Great. The Struggle for Power, 1671-1725, 427. El título del Código de Prusia (1794), era "Allgemeines Landrecht für die preußischen Staaten": "los estados" en plural. Ver las formulas "el Rey de Prusia y de sus estados", o "sus provincias". Para las fuentes en ruso, ver por ejemplo "todos los gosudarstva del imperio ruso...", Acta annonçant l'élection de Mikhail Romanov, in POZDEEVA, Irina V. "Pervye Romanovy i tsaristskaia ideia (XVII vek)" (Los primeros Romanov y la concepción zarista en el siglo XVII), Voprosy istorii, 1996, núm. 1, p. 48. Otros ejemplos en PSZ, t.1, doc. núm. 69, p. 114; ZHIVOV, Viktor M. Iz tserkovnoi istorii vremen Petra Velikogo, (Sobre la historia eclesiástica bajo Pedro el Grande), NLO, Moscú, 2004), nota 5, p. 82 (Carta d'Aleksei Miljailovich, 1677).

${ }^{72}$ Pedro "broke the identification of the person of the tsar with the state and insisted that the populace take two separate oaths, one to the ruler, and one to the state ", WHITTAKER, Cynthia H. "The Reformng Tsar: The Redefinition of Autocratic Duty in Eighteenth-Century Russia", Slavic Review, 1992, vol. 51, núm. 1, pp. 82-84.

${ }^{73}$ SHENNAN, J.H. The Origins of the Modern European State 1450-1725, London, 1974, p. 65; DYSON, Kenneth The State tradition in Western Europe: a Study of an Idea and Institution, Oxford University Press, New York, 1980, p. 31.
} 
invocado por Pedro es el Estado. La ausencia de una reflexión crítica acerca del uso del significante gosudarstvo autoriza estas re-interpretaciones en cadena que no vuelven a las fuentes y no se preguntan por la historicidad de los conceptos. Así, la frase prudente de Solovev se transforma en afirmación de algo que él nunca escribió y que no existió, mientras que el concepto contemporáneo "Estado" sustituye a la palabra gosudarstvo.

La fidelidad debida ante todo al Amo/Señor, y a veces, según las circunstancias, a los intereses del Imperio ${ }^{74}$ que le pertenece está en armonía con la lógica interna de un sistema en el cual esta fidelidad es también su impronta. Este sistema es a la vez coherente y ajeno al orden estatal propio de la Época contemporánea. Aislando la fórmula "fidelidad al Gosudarstvo", y convirtiéndola en el primer indicio de una mentalidad estatal contemporánea, no solamente se cae en un anacronismo perjudicial sino que además se deja de lado la coherencia interna de la autocracia de la época de Pedro y se evita el análisis, ciertamente difícil, de su complejidad. Esta es la situación ahistórica que la investigación en clave histórico-conceptual permite superar. El envejecimiento arbitrario de la "modernidad política" alimenta la incomprensión -no siempre despojada de segundas intenciones políticas- de las transformaciones revolucionarias en las que Rusia se debatirá dos siglos después.

Buenos Aires, diciembre de 2017.

${ }^{74}$ El "interés del Imperio" se reducía al de la autocracia: PLOTNIKOV, A.B. "Ogranichenie samoderzhaviia v Rossii v 1730 g. : idei i formy", p. 63. 